OPEN ACCESS

Edited by:

Inga Mewis,

Humboldt University of

Berlin, Germany

Reviewed by:

Radmila Pavlovic,

University of Milan, Italy

Waseem Gul,

ElSohly Laboratories Inc,

United States

${ }^{*}$ Correspondence:

Mark Lefsrud

mark.lefsrud@mcgill.ca

Specialty section:

This article was submitted to

Plant Metabolism and Chemodiversity,

a section of the journal

Frontiers in Plant Science

Received: 21 October 2020 Accepted: 07 May 2021

Published: 31 May 2021

Citation:

Desaulniers Brousseau V, Wu B-S,

MacPherson S, Morello $V$ and

Lefsrud M (2021) Cannabinoids and

Terpenes: How Production of

Photo-Protectants Can Be

Manipulated to Enhance Cannabis

sativa L. Phytochemistry.

Front. Plant Sci. 12:620021.

doi: 10.3389/fpls.2021.620021

\section{Cannabinoids and Terpenes: How Production of Photo-Protectants Can Be Manipulated to Enhance Cannabis sativa L. Phytochemistry}

\author{
Vincent Desaulniers Brousseau, Bo-Sen Wu, Sarah MacPherson, Victorio Morello and \\ Mark Lefsrud *
}

Department of Bioresource Engineering, McGill University, Sainte-Anne-de-Bellevue, QC, Canada

Cannabis sativa L. is cultivated for its secondary metabolites, of which the cannabinoids have documented health benefits and growing pharmaceutical potential. Recent legal cannabis production in North America and Europe has been accompanied by an increase in reported findings for optimization of naturally occurring and synthetic cannabinoid production. Of the many environmental cues that can be manipulated during plant growth in controlled environments, cannabis cultivation with different lighting spectra indicates differential production and accumulation of medically important cannabinoids, including $\Delta^{9}$-tetrahydrocannabinol $\left(\Delta^{9}\right.$-THC), cannabidiol (CBD), and cannabigerol (CBG), as well as terpenes and flavonoids. Ultraviolet (UV) radiation shows potential in stimulating cannabinoid biosynthesis in cannabis trichomes and pre-harvest or post-harvest UV treatment merits further exploration to determine if plant secondary metabolite accumulation could be enhanced in this manner. Visible LED light can augment THC and terpene accumulation, but not CBD. Well-designed experiments with light wavelengths other than blue and red light will provide more insight into light-dependent regulatory and molecular pathways in cannabis. Lighting strategies such as subcanopy lighting and varied light spectra at different developmental stages can lower energy consumption and optimize cannabis PSM production. Although evidence demonstrates that secondary metabolites in cannabis may be modulated by the light spectrum like other plant species, several questions remain for cannabinoid production pathways in this fast-paced and growing industry. In summarizing recent research progress on light spectra and secondary metabolites in cannabis, along with pertinent light responses in model plant species, future research directions are presented.

\footnotetext{
Keywords: light emitting diode, light spectrum, light wavelength, photobiology, secondary metabolites, tetrahydrocannabinol, ultraviolet
}

\section{INTRODUCTION}

Secondary metabolites from plants, animals, and microorganisms drive many medical and pharmacological applications, building on thousands of years of traditional medicine (Stojanoski, 1999). In depth characterization of isolated plant secondary metabolites (PSM) for medical treatment started at least 200 years ago, and it has progressed exponentially during the last 
30 to 40 years (Okada et al., 2010). One notable and historical medical application is the isolation of morphine from poppy (Papaver somniferum) seed oil in the early 1800s (Krishnamurti and Rao, 2016). This alkaloid and its derivatives, opiates, are used for managing pain, yet they have contributed to a deadly and costly opioid crisis because of their addictive nature (Dasgupta et al., 2018).

The cannabis plant (Cannabis sativa L.) possesses more than 500 known PSM, including cannabinoids, terpenes, and flavonoids (Elsohly et al., 2017; Solymosi and Köfalvi, 2017; Gonçalves et al., 2019). Research on cannabis PSM has grown rapidly because of therapeutic potential. The cannabinoid $\Delta^{9}$-tetrahydrocannabinol ( $\Delta^{9}$-THC), a hallmark of medical cannabis, reportedly exerts anticancer (White et al., 1976), antibacterial (Van Klingeren and Ten Ham, 1976), antiemetic (Garb, 1981), and analgesic action via modulation of the endocannabinoid system (Mao et al., 2000), and it remains a possible alternative to opiates for managing neuropathies and treatment-resistant spasticity (Abrams, 2019). Specific cannabinoid-terpenoid ratios from herbal extracts have shown further promise (Gonçalves et al., 2019), and provide support for the "entourage effect," the postulated synergistic action of cannabinoids and terpenes with notable examples in pain management (Johnson et al., 2010), analgesia (Gallily et al., 2015), cancer (Blasco-Benito et al., 2018), and severe epilepsy (Goldstein, 2016).

Prior to cannabis legalization, our knowledge of cannabis PSM production primarily stemmed from illegal production operations (Vanhove et al., 2011). Over the last few years, enormous progress has been made toward advancing cannabisrelated medicine (Hutchison et al., 2019) and cannabis biotechnology (i.e., productivity and molecular biology) (Hesami et al., 2020). Phytochemical characterization of a given cultivar (or the newly coined term "chemovar"), including biochemical and pharmacological properties, could drive this next era of medicine forward (Russo, 2019), but thorough understanding of cannabis PSM production and accumulation mechanisms

\footnotetext{
Abbreviations: CBC, cannabichromene; CBCA, cannabichromentic acid; CBCAS, cannabichromentic acid synthase; CBDAS, cannabidiolic acid synthase; CBD, cannabidiol; CBDA, cannabidiolic acid; CBG, cannabigerol; CBGA, cannabigerolic acid; CBL, cannabicyclol; CBLA, cannabicyclolic acid; CBN, cannabinol; CBNA, cannabinolic acid; CHS, chalcone synthase; CHI, chalcone isomerase; CsOMT21, C. sativa $\mathrm{L}$. O-methyltransferase 21; CsPT3, C. sativa $\mathrm{L}$. prenyltransferase 3; $\mathrm{C} 4 \mathrm{H}$, cinnamate 4-hydroxylase; $\mathrm{C} 3 \mathrm{H}$, p-coumaroyl-CoA 3-hydroxylase; DMAPP, dimethylallyl pyrophosphate; DXS, 1-deoxy d-xylulose-5-phosphate synthase; DXP, 1-deoxy-D-xylulose 5- phosphate; FNS, flavone synthase; FPP, farnesyl diphosphate; FPPS, farnesyl diphosphate synthase; F3'H, flavonoid 3'-hydrolase; G3P, glyceraldehyde 3-phosphate; GPP, geranyl pyrophosphate; GPPS, geranyl pyrophosphate synthase; HEDS or HvCHS, homoeriodictyol/eriodictyol synthase; HPS, high pressure sodium; IPP, isopentenyl diphosphate; IPPi, isopentenyldiphosphate delta-isomerase; LED, light-emitting diode; LS, limonene synthase; MEP, methylerythritol phosphate; MEV, mevalonate; OA, olivetolic acid; OAC, olivetolic acid cyclase; OMT, SAM-methyltransferase; PAL, phenylalanine ammonia-lyase; PSM, plant secondary metabolite; PT4, geranylpyrophosphate: olivetolate geranyltransferase $4 ; \Delta^{8}$-THC, $\Delta^{8}$-tetrahydrocannabinol; $\Delta^{9}$-THC (or THC), $\Delta^{9}$-tetrahydrocannabinol; THCA, tetrahydrocannabinolic acid; THCAS, tetrahydrocannabinolic acid synthase; THCV, tetrahydrocannabivarin; TPS, terpene synthase; TK, tetraketide; TKS, tetraketide synthase; UV, ultraviolet; 4CL, 4-Coumarate:CoA ligase.
}

are required. Contemporary medicine highlights cannabinoids, terpenes, and flavonoids as promising PSMs for treating multiple ailments (Aliferis and Bernard-Perron, 2020).

Evidence suggests that growing conditions (i.e., light, nutrients, temperature, and microbiome) can be manipulated to improve and optimize production of specific compounds. Light triggers plant secondary metabolism and PSM accumulation, although how optical and spectral properties (i.e., wavelength, bandwidth, and intensity) impact cannabis PSM production remains unclear (Hawley, 2018; Magagnini et al., 2018; Namdar et al., 2019). This review aims to bridge the gap between light properties and cannabis PSM production, by recalling PSM origin and function in plants. An overview of the cannabis PSM biosynthesis, including cannabinoid, terpene, and flavonoid, is provided in the support of the "entourage effect" (Baron, 2018; Tomko et al., 2020). Available light study findings on cannabis PSM production in response to different light treatments are summarized, with an emphasis on ultraviolet (UV) radiation during plant growth.

\section{EVOLUTIVE PERSPECTIVE OF PLANT SECONDARY METABOLITES}

PSM are assembled from primary metabolite precursors (Seca and Pinto, 2019). These PSM are not essential to plants' survival; rather, they allow plants to withstand abiotic and biotic stress (drought or water stress, light or predatory stress) (Bourgaud et al., 2001). PSM molecular pathways are conserved between plant families through gene clusters. Genome sequencing has shown that these gene clusters are highly conserved between plants of different families because of their shared evolutive origin (Nützmann et al., 2016). In C. sativa L., cannabinoid and terpene biosynthesis reportedly contributes to protection against UV radiation and chemical stressors created to combat insects (Pate, 1994; Benelli et al., 2018).

PSM likely evolved in an environment where biotic stressors played a lesser role in driving evolutive adaptation (Tossi et al., 2019). By looking at other PSM functions and their role in the plant's response to abiotic stress, one theory states that to survive in shallow water, ancestral algae evolved mechanisms to survive in an environment with elevated UV radiation $(<380 \mathrm{~nm})$, a primordial abiotic stressor (Akula and Ravishankar, 2011; Jenkins, 2017). UV radiation leads to damaged DNA and photosystems, resulting in reduced production (Teramura, 1983). Plants evolved mechanisms to protect against this radiation stress by accumulating phenolic and terpenoid compounds that absorb UV radiation and acted as sunscreen in leaves (Rozema et al., 2002). This allowed photosynthetic organisms to grow in new ecological niches, while exposing themselves to increasing UV radiation (Tossi et al., 2019). This theory is supported by the apparition of a highly conserved receptor, UV-B Resistance 8 (UVR8) in terrestrial plants that mediates plant photomorphogenesis in response to UV radiation (Jenkins, 2017; Tossi et al., 2019). Parallel to the abiotic stress response, the large diversity of PSM can also be explained by exposure to biotic stress and 
the co-evolution of insects and plants during terrestrialization in the Neoproterozoic era (1,000 to 541 million years ago) (Theis and Lerdau, 2003; Labandeira, 2005). Plants evolved attractant and deterrent cues through their PSM to favor pollination and decrease predation (Kessler and Halitschke, 2007). Studies report that cannabis PSM extracts, specifically hemp extracts, effectively repel insects (Mcpartland, 1997; Benelli et al., 2018). The cannabis microbiome also influences plant metabolism. A recent review highlights promising avenues of PSM modulation in cannabis through endophytes (Taghinasab and Jabaji, 2020).

\section{TRICHOMES AND CANNABIS PROFILING}

\section{Trichomes}

Trichomes form a large group of plant structures that are unior multicellular epidermal appendages, classified by their origin, form, function, and secretion (Werker, 2000). These structures are responsible for synthesis and storage of cannabinoids and terpenes in C. sativa L., accumulating in resin heads (Hudson, 1963). They protect plants from light stress (Lydon et al., 1987), high heat (Levin, 1973; Lapinjoki et al., 1991), and herbivore pressure (Pillemer and Tingey, 1976; Alahakoon et al., 2016). Other mechanisms, including water absorption through dew collection, salt secretion, and alluring function, are reported (Werker, 2000).

All aerial parts of the cannabis plant are covered with trichomes, and can be classified as either "glandular" or "non-glandular" (Dayanandan and Kaufman, 1976). Glandular trichomes contain more bioactive/psychoactive compounds than non-glandular trichomes (Raman et al., 2017; Livingston et al., 2020). Glandular trichomes are found on all anatomical plant parts except the hypocotyl and cotyledon, and non-glandular trichomes are found on stems, leaves, petioles, stipules, bract, and tepals (Raman et al., 2017).

Glandular trichome classification relates to morphological traits and composition of the chemical substance secreted (Werker, 2000). Three types of glandular trichomes in the cannabis plant are described and size-differentiated: capitatestalked, capitate-sessile, and bulbous trichomes (Dayanandan and Kaufman, 1976; Hammond and Mahlberg, 1977). Capitatestalked trichomes are found exclusively on flowering regions, whereas capitate-sessile and bulbous trichomes are found everywhere except the hypocotyl and cotyledon (Raman et al., 2017). In C. sativa L., high THC-containing strains had a bigger resin head on their glandular trichomes than in lowTHC industrial hemp (Small and Naraine, 2016). Capitatestalked glandular trichomes have more secretory disc cells than other plants and secrete specialized metabolites in the subcuticular oil storage cavity, instead of through pores formed in the cuticle (Tissier, 2012; Huchelmann et al., 2017). Excretory cells secrete a resin in a subcuticular cavity (Small and Naraine, 2016). This resin contains high concentrations of the economically important cannabinoids, with psychoactive and medicinal properties (Dayanandan and Kaufman, 1976; Small and Naraine, 2016). Optimal cannabinoid and terpene biosynthesis in glandular trichomes is of paramount importance to bud quality (El-Alfy et al., 2010; Friedman and Devinsky, 2015).

\section{Cannabinoids and Cannabis Profiling}

Cannabinoids, also called meroterpenes or terpenophenols, are PSM synthesized by members of the Cannabaceae family, and several other plant species, including Echinacea purpurea, Echinacea angustifolia, Acmella oleracea, Helichrysum umbraculigerum, and Radula marginata (Bauer et al., 2008). More than 20\% of isolated cannabis PSMs are cannabinoids (Chandra et al., 2017). The two major cannabinoids, $\Delta^{9}$-THC and cannabidiol (CBD), are used to classify cannabis (Bruci et al., 2012; Piluzza et al., 2013; Hilderbrand, 2018), and differentiation between marijuana and hemp is often based on $\Delta^{9}$-THC content from cannabis biomass. Cannabis extract with a $\Delta^{9}-\mathrm{THC}$ percentage greater than $0.3 \%$ is classified as a medical marijuana product, whereas $C$. sativa $\mathrm{L}$. with a $\Delta^{9}$-THC content of less than $0.3 \%$ is cultivated as hemp (Hilderbrand, 2018). Three C. sativa $\mathrm{L}$. chemotypes have further been distinguished and classified, determined by the relative proportions of $\Delta^{9}$-THC and CBD: drug-type ( $\Delta^{9}$-THC is the predominant cannabinoid, known as marijuana), intermediate-type (both $\Delta^{9}$-THC and CBD are predominant), and fiber-type (CBD is the predominant cannabinoid, known as hemp) (Bruci et al., 2012; Piluzza et al., 2013). This differentiation based on cannabinoid content or cannabis cultivars is inadequate, particularly for the medical industry, since it does not reflect or match the therapeutic and medical properties (Russo, 2019). The term "chemovar," which considers the specific ratios of cannabinoids, flavonoids, and terpenes, will likely be a better tool in the development of cannabis-assisted medicine (Baron, 2018).

\section{CANNABIS PSMS AND BIOSYNTHESIS}

Changes in PSM biosynthesis during ontological development of cannabis are well-studied, starting with cannabinoid and monoterpene concentrations in flowers in the first weeks of the flowering phase, and ending with almost four times the quantity in a matter of 7 weeks (Aizpurua-Olaizola et al., 2016). At least 113 cannabinoids and 120 terpenes have been identified (Elsohly and Slade, 2005; Elsohly and Gul, 2014; Ahmed et al., 2015), and they are heavily concentrated in virgin female inflorescence (Turner et al., 1980). PSMs are usually extracted from this, as maximal PSM accumulation is often found in glandular trichomes. Other studies have concentrated on determining the role that flavonoids play in cannabis physiology, and how cannabis-specific flavonoids may be exploited (Barrett et al., 1985; Pollastro et al., 2018).

\section{Cannabinoids}

Figure 1 shows the cannabinoid biosynthesis pathway and precursor formation. Primary biosynthesis steps are impacted by UV radiation and blue light (Dolzhenko et al., 2010; Booth et al., 2017; Jin et al., 2019; Nazari and Zarinkamar, 2020). Cannabinoid biosynthesis starts as isopentenyl diphosphate (IPP), formed from glyceraldehyde 3-phosphate (G3P), and pyruvate in plastids (Mcgarvey and Croteau, 1995). Formation of IPP in plastids is 


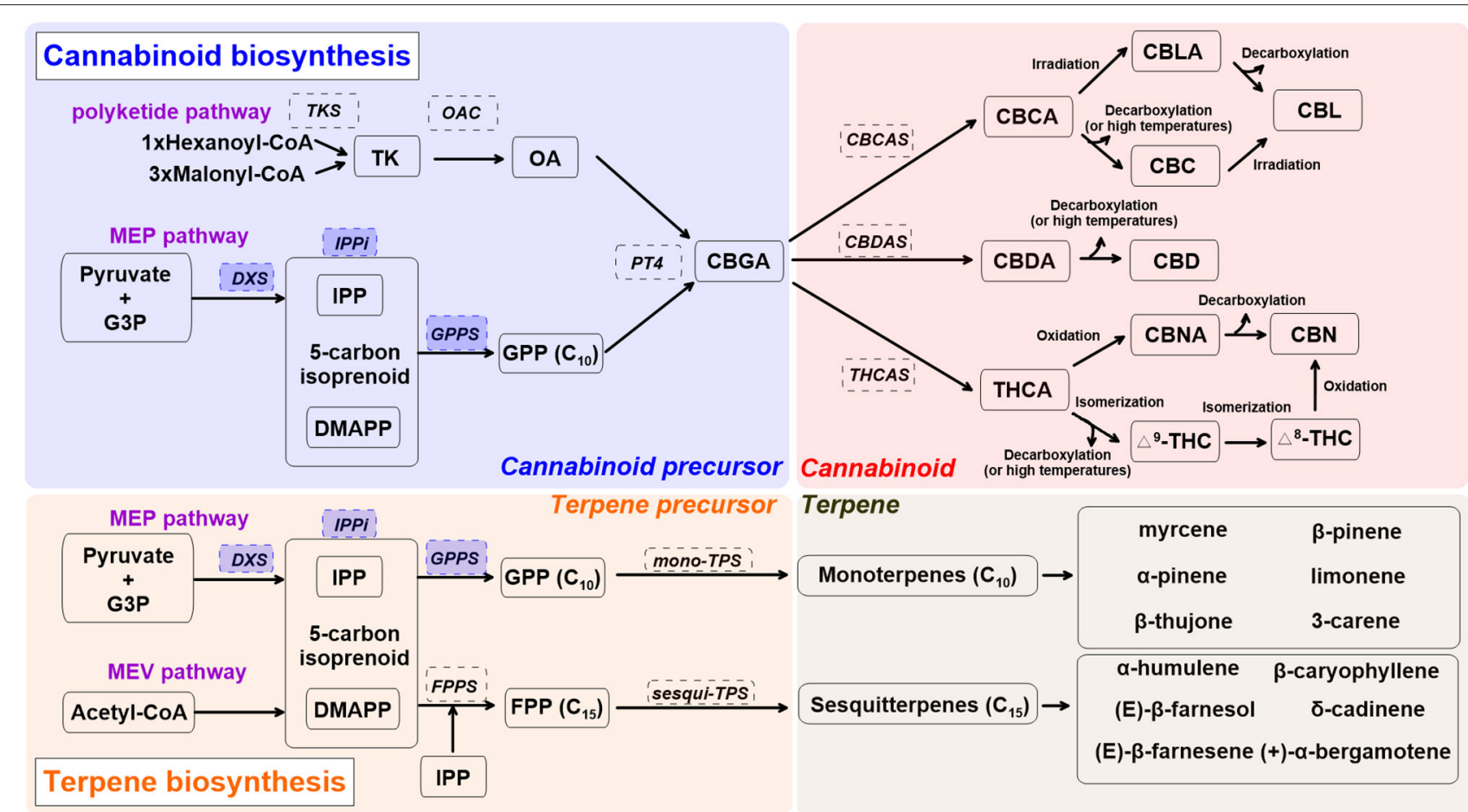

FIGURE 1 | A simplified overview of cannabinoid and terpene biosynthesis pathways in cannabis (Cannabis sativa L.), derived from recent reviews (Hazekamp, 2007 Degenhardt et al., 2017; Sirikantaramas and Taura, 2017; Jin et al., 2019). Enzymes are in dashed line box. Enzymes in shaded blue boxes are upregulated by UV radiation and blue light in Lamiaceae. Cannabis precursor (shade blue): CBDA, cannabidiolic acid; DMAPP, dimethylallyl pyrophosphate; G3P, glyceraldehyde 3-phosphate; GPP, geranyl pyrophosphate; GPPS, geranyl pyrophosphate synthase; MEP, methylerythritol phosphate; PT4, geranylpyrophosphate: olivetolate geranyltransferase 4; IPP, isopentenyl diphosphate; IPPi, isopentenyl-diphosphate delta-isomerase; OA, olivetolic acid; OAC, olivetolic acid cyclase; TK, tetraketide; TKS, tetraketide synthase. Cannabinoid (shade red): CBC, cannabichromene; CBCA, cannabichromentic acid; CBCAS, cannabichromentic acid synthase; CBDAS, cannabidiolic acid synthase; CBD, cannabidiol; CBG, cannabigerol; CBGA, cannabigerolic acid; CBL, cannabicyclol; CBLA, cannabicyclolic acid; CBN, cannabinol; CBNA: cannabinolic acid; $\Delta^{8}$-THC, $\Delta^{8}$-tetrahydrocannabinol; $\Delta^{9}$-THC (or THC), $\Delta^{9}$-tetrahydrocannabinol; THCA, tetrahydrocannabinolic acid. Terpene precursor (shade orange): FPP, farnesyl diphosphate; FPPS, farnesyl diphosphate synthase; MEV, mevalonate; TPS, terpene synthase.

ensured by 1-deoxy d-xylulose-5-phosphate synthase (DXS), part of the methylerythritol phosphate (MEP) pathway (Lichtenthaler, 1999). The 5-carbon isoprenoid then is linked with isopentenyl diphosphate (IPP) and dimethylallyl pyrophosphate (DMAPP) through isopentenyl-diphosphate delta-isomerase (IPPi). These are condensed into geranyl diphosphate (GPP, $\mathrm{C}_{10}$ ) via GPP synthase (GPPS) (Ruzicka, 1953; Hunter, 2007). GPP also acts as a precursor for monoterpene biosynthesis. The enzymes DXS, IPPi, and GPPS are upregulated by UV radiation and blue light in peppermint (Mentha $x$ piperita) and water mint (Mentha aquatica) (Dolzhenko et al., 2010; Nazari and Zarinkamar, 2020).

Olivetolic acid (OA) sets cannabinoid and monoterpene biosynthesis apart. It is produced through a type III polyketide synthase, leading to formation of the cannabinoid precursor, cannabigerolic acid (CBGA) (Gagne et al., 2012). The first step of $\mathrm{OA}$ formation is ensured by a unique tetraketide synthase (TKS) and olivetolic acid cyclase (OAC) (Luo et al., 2019). This step uses 1 hexanoyl-CoA and 3 malonylCoA to form OA via a tetraketide (TK) intermediate. $\mathrm{OA}$ is then prenylated by geranylpyrophosphate: olivetolate geranyltransferase 4 (PT4) to form the central precursor molecule CBGA, which can then be further modified into constituents such as $\Delta^{9}$-THC, $\mathrm{CBD}$, and cannabichromene (CBC) (Flores-Sanchez and Verpoorte, 2008b; Luo et al., 2019). CBGA is converted to cannabidiolic acid (CBDA), tetrahydrocannabinolic acid (THCA), and cannabichromentic acid (CBCA) by cannabidiolic acid synthase (CBDAS), tetrahydrocannabinolic acid synthase (THCAS), and cannabichromentic acid synthase (CBCAS), respectively. During these steps, cannabinoids are naturally converted from their acid forms during storage or heating (decarboxylation) as non-enzymatic catalyzed reactions (Veress et al., 1990). THCA and CBDA reactions are oxygen-dependent and produce hydrogen peroxide, as opposed to the CBCA reaction, which is oxygen-independent and can be inhibited by hydrogen peroxide (Sirikantaramas et al., 2004; Taura et al., 2007; Degenhardt et al., 2017).

CBCA is most actively synthesized in young cannabis seedlings and can be found in both drug-type and fiber-type cannabis plants, yet its concentration is relatively low compared to other cannabinoids (Kushima et al., 1980; Chandra et al., 2017). CBCA is converted to CBC (Gaoni and Mechoulam, 1966), cannabicyclolic (CBL), and cannabicyclolic acid (CBLA) through irradiation or decarboxylation (Shoyama et al., 1972). CBDA is the precursor of CBD, and THCA is the acidic precursor 
of $\Delta^{9}$-THC. THCA can be converted to $\Delta^{8}$-THC, cannabinol $(\mathrm{CBN})$, and cannabinolic acid (CBNA) (Mechoulam and Gaoni, 1965; Elsohly and Slade, 2005).

\section{Terpenes}

Terpenes are a large class of organic molecules responsible for flower aroma; they include $\beta$-caryophyllene, limonene, and linalool, which are present in 50 to $70 \%$ of all studied plants (Knudsen et al., 2006; Booth et al., 2017). For monoterpene biosynthesis, GPPS condenses one unit of IPP and DMAPP to form GPP, and GPP is converted into monoterpene form via mono-terpene synthase (TPS). Sesquiterpene biosynthesis requires two units of IPP to be added to a DMAPP unit. This sequential modification of DMAPP is ensured by farnesyl diphosphate synthase (FPPS) (Kulkarni et al., 2013). FPP is converted into sesquiterpenes via sesqui-TPS (Booth et al., 2017). Involvement of other enzymes such as cytochrome P450s leads to more complex terpenes (diterpenes, $\mathrm{C}_{20}$ ) (Grof, 2018; Booth and Bohlmann, 2019).

Independent of the inflorescence stage, major monoterpenes found in indoor-grown $C$. sativa L. "Finola" are $\alpha$-pinene, $\beta$-pinene, $\beta$-ocimene, limonene, myrcene, and terpinolene (Booth and Bohlmann, 2019). Major sesquiterpenes expressed in trichomes are $\alpha$-humulene, $\beta$-caryophyllene, bergamotene, and farnesene. As inflorescence matures, monoterpene accumulation increases relative to sesquiterpenes (Figure 1) (Booth et al., 2017). Although more than 120 terpenes have been identified in C. sativa L., many (including corresponding TPS genes) require further characterization (Aizpurua-Olaizola et al., 2016; Booth and Bohlmann, 2019). Since robust analytical standards are lacking, reported terpene profiles in $C$. sativa L. may contain some unknown terpene compounds, especially sesquiterpenes. A recent study reported more than 30 different TPS genes in the "Purple Kush" genome, and only 9 of 30 have been characterized (Günnewich et al., 2007; Booth et al., 2017). Elucidation of the underlying mechanisms surrounding terpene biosynthesis in cannabis plants may lead to further exploration and different medical applications for this PSM group (Aliferis and Bernard-Perron, 2020).

Terpenoids (a modified class of terpenes with different functional groups) are by far the most diverse group, with at least 80,000 different compounds (Christianson, 2017; Zhou and Pichersky, 2020). In recent years, cannabis terpenoids have slowly gained interest (Arena et al., 2016; Booth et al., 2017; Mudge et al., 2019). Studies have reported that terpenoids are powerful metabolites that have an interactive effect (or an "entourage effect") with cannabinoid receptors (Gertsch et al., 2008). However, terpene composition in cannabis resin is dependent upon genetic, environmental, and developmental factors, and highly variable terpene profiles additionally exist between individual plants (Fischedick et al., 2010; Hazekamp and Fischedick, 2012; Booth et al., 2017). Terpene diversity in cannabis resin is responsible for scent and flavor qualities of cannabis flowers (Booth et al., 2017).

\section{Flavonoids}

Members of the phenol family, flavonoids, form an important PSM group that aids in the plant's responses to sunlight and UV radiation (Downey et al., 2006; Warner et al., 2021). More than 20 flavonoid types in C. sativa $\mathrm{L}$. have been identified, such as quercetin and kaempferol (Brenneisen, 2007). Others, such as cannflavins A, B, and C, are uniquely found in cannabis (Barrett et al., 1985, 1986; Radwan et al., 2008). Cannabis-specific flavonoids show promising therapeutic effects because of their anti-inflammatory activities (Barrett et al., 1985, 1986).

Cannabis-specific flavonoid biosynthesis is not wellestablished. Figure 2 shows the proposed biosynthetic pathway(s) for cannflavin A and B in C. sativa L. (Flores-Sanchez and Verpoorte, 2008b; Rea et al., 2019). The general pathway for cannflavin biosynthesis begins with $p$-coumaroyl-CoA derived from phenylalanine, phenylalanine ammonia-lyase (PAL), cinnamate 4-hydroxylase $(\mathrm{C} 4 \mathrm{H})$, and 4-Coumarate:CoA ligase (4CL). p-coumaroyl is covered to luteolin and cannflavin A and $B$ via regiospecific methylation and prenylation reactions (Rea et al., 2019). Alternate routes for cannflavin A/B biosynthesis, beginning with feruloyl-CoA or caffeoyl-CoA with 3 malonylCoA, are also proposed (Flores-Sanchez and Verpoorte, 2008b). Although it has not been reported in C.sativa L., upregulated chalcone synthase (CHS) gene expression is observed in several plant species under abiotic stress such as UV radiation, as well as biotic stressors such as bacterial or fungal infection (Lipphardt et al., 1988; Dao et al., 2011).

Unlike cannabinoids and terpenes, flavonoid spatial and temporal distribution in cannabis plants does not follow the same pattern (Aizpurua-Olaizola et al., 2016). Rather, higher flavonoid content is reported in C. sativa $\mathrm{L}$. leaves than other plant tissues (Flores-Sanchez and Verpoorte, 2008a; Jin et al., 2020). Apart from this, flavonoid concentration seems to decrease with plant tissue age (both leaves and inflorescence), in which higher flavonoid content is observed in young cannabis plants (FloresSanchez and Verpoorte, 2008a; Drinić et al., 2018). Low flavonoid content in cannabis oil and seeds is reported (Frassinetti et al., 2018; Moccia et al., 2019; Siano et al., 2019), while flavonoids are absent in glandular trichomes (Flores-Sanchez and Verpoorte, 2008b).

Recent studies show that flavonoid accumulation in inflorescence is variety-dependent and could be an indicator of the susceptibility of the variety to oxidative stress (Pavlovic et al., 2019; Giupponi et al., 2020). Pavlovic et al. (2019) reported the hemp variety "Futura 75" had higher cannabispiran concentration than "Finola." This variety-dependent response is displayed elsewhere, where the hemp variety "Carmagnola Cs" has up to $25 \%$ more total phenol content (TPC) than other varieties, such as "Kompolti" (Izzo et al., 2020). Harnessing the radical scavenger activity and screening ability of flavonoids against UV radiation is a promising means of increasing flavonoid production in medical varieties (Agati and Tattini, 2010). Although it is out of the scope in this review, it is still worth to mention that the differences in the flavonoid quantifying methodologies, such as solvents used, matrix to solvent ratio, and characterization methods may result in 


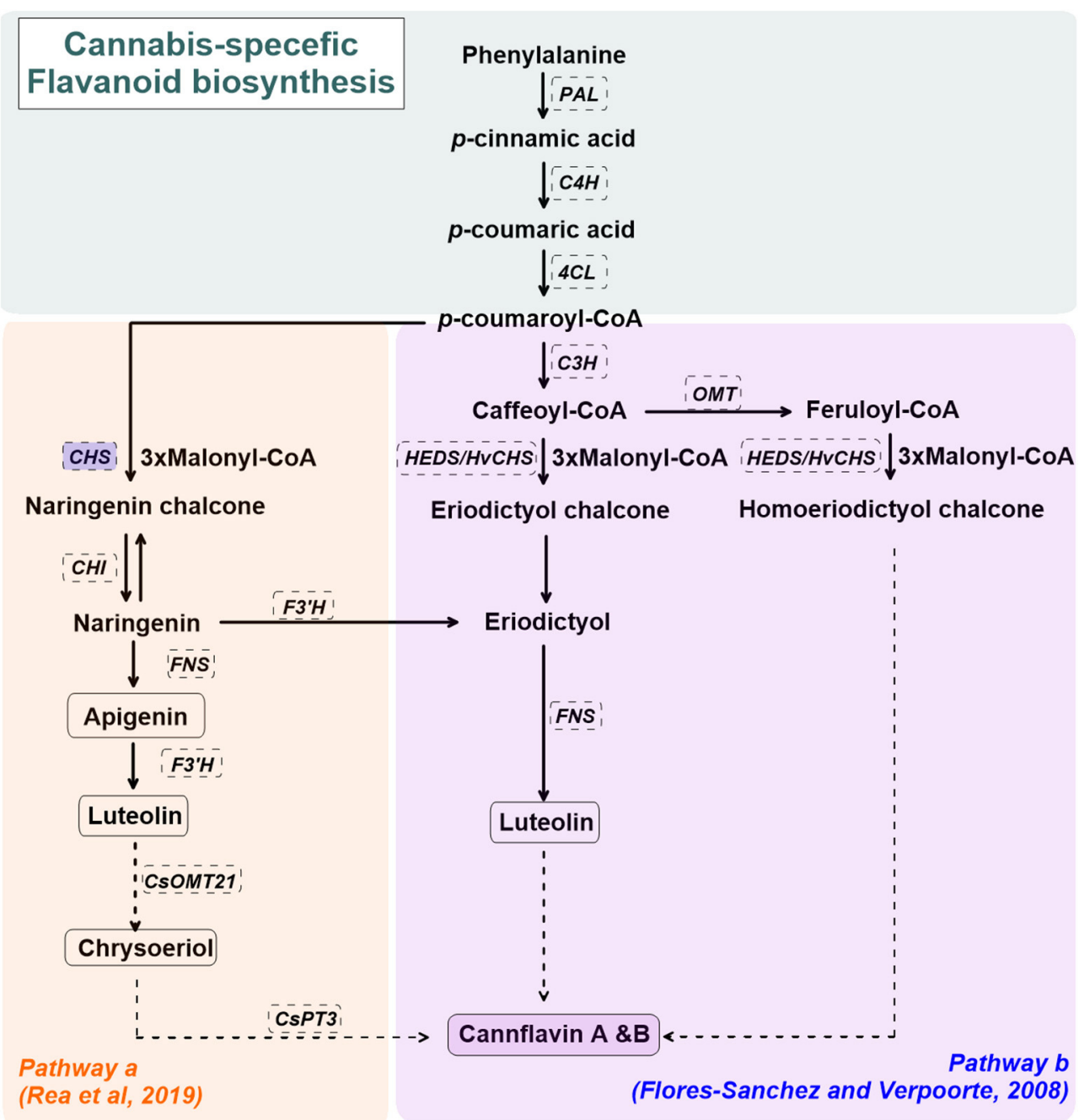

FIGURE 2 | A simplified overview of the cannabis flavonoids, cannflavin A\&B, pathway(s) in cannabis (Cannabis sativa L.), derived from Flores-Sanchez and Verpoorte (2008b) and Rea et al. (2019). Enzymes are in dashed line box. Enzymes in shaded blue boxes are upregulated by UV radiation in Arabidopsis thaliana. Dashed arrows represent proposed enzymatic reactions. CHS, chalcone synthase; CHI, chalcone isomerase; CsOMT21, C. sativa L. O-methyltransferase 21; CsPT3, C. sativa L. prenyltransferase 3; C4H, cinnamate 4-hydroxylase; C3H, p-coumaroyl-CoA 3-hydroxylase; FNS, flavone synthase; F3'H, flavonoid 3'-hydrolase; HEDS or $\mathrm{HvCHS}$, homoeriodictyol/eriodictyol synthase; OMT, SAM-methyltransferase; PAL, phenylalanine ammonia-lyase; 4CL, 4-Coumarate:CoA ligase.

flavonoid concentration discrepancies (Drinić et al., 2018; Frassinetti et al., 2018; Pellati et al., 2018).

\section{THE IMPACT OF LIGHT SPECTRUM ON CANNABIS PSM PRODUCTION}

Plants respond to light stress by producing and accumulating PSM (Thirumurugan et al., 2018). The impact of UV radiation $(>380 \mathrm{~nm})$ and the visible light spectrum $(380-740 \mathrm{~nm})$ on PSM in greenhouse-grown crops has been well-studied (Urban et al., 2016; Gupta et al., 2017; Alrifai et al., 2019). However, the specific effects of light, including light properties (wavelength and intensity) and fixture configuration (i.e., overhead and subcanopy lighting) on cannabis PSM and phytochemistry is limited and not well-understood (Andre et al., 2016). These studies primarily focused on PSM accumulation in leaves rather than floral biomass. Table 1 summarizes available studies aimed at determining the impact of light spectrum and lighting configurations on cannabinoid and terpene accumulation.

\section{UV Radiation and PSM}

Different wavelength ranges in UV radiation result in varying cannabinoid accumulation (Lydon et al., 1987; Magagnini et al., 2018). It has been nearly four decades since the first study suggesting that UV-B $(280-315 \mathrm{~nm})$ radiation affects cannabinoid accumulation in cannabis plants (Lydon et al., 1987). UV-B radiation did not impact cannabinoid content in both drug- and fiber-type cannabis plants, with the exception of $\Delta^{9}$-THC in bud tissues of drug-type cannabis plants. When the daily dosage of UV-B radiation increased from 0 to $13.4 \mathrm{~kJ} \mathrm{~m}^{-2}$, 
TABLE 1 | A comparison of cannabis PSM yield data compiled with overhead, subcanopy, or supplemental lighting.

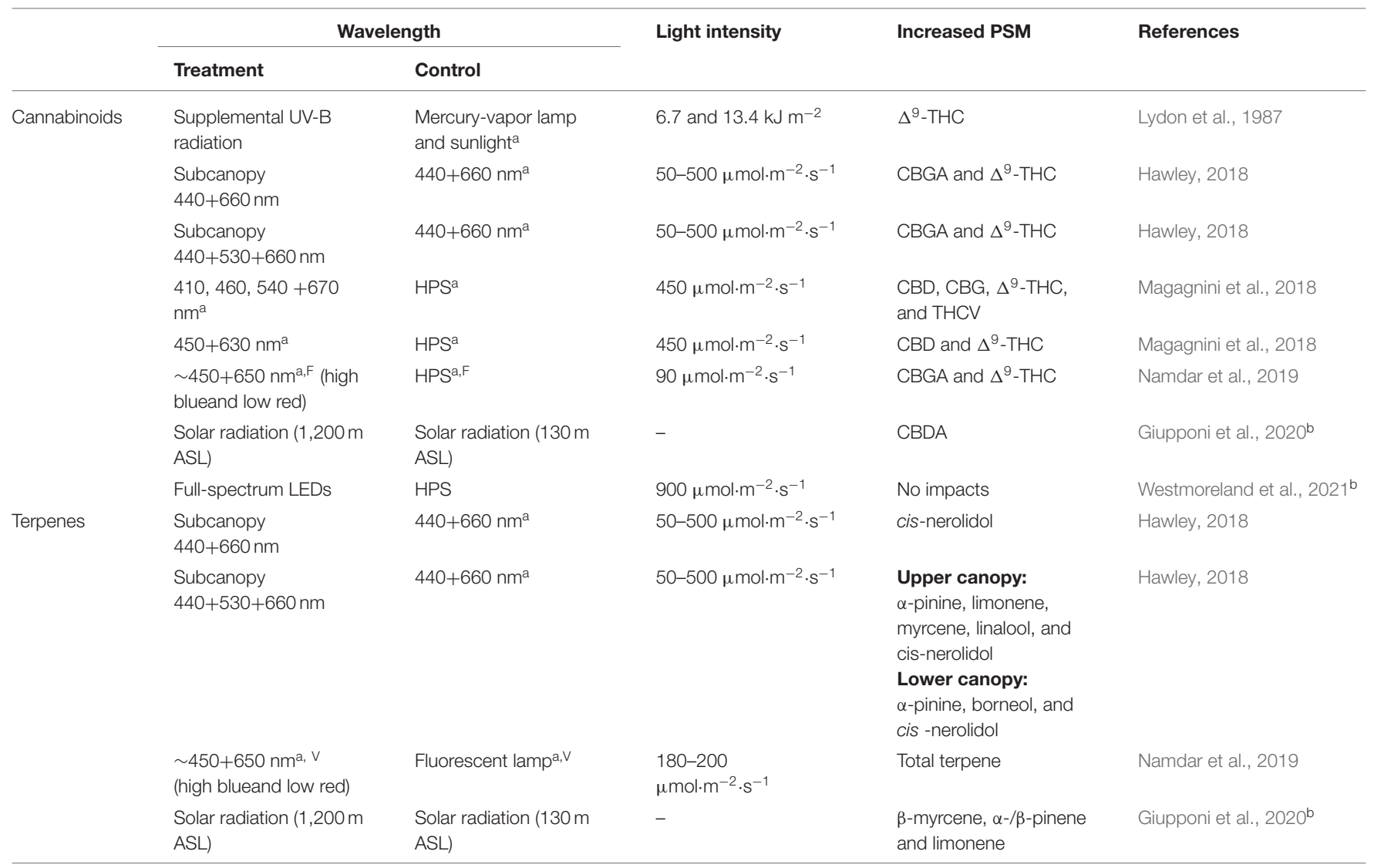

a Overhead lighting; ${ }^{b}$ fiber-type cannabis (hemp); ASL, above sea level; CBD, cannabidiol; CBG, cannabigerol; CBGA, cannabigerolic acid; F, flowering stage; $\Delta^{9}-T H C, \Delta^{9}$ tetrahydrocannabinol; THCV, tetrahydrocannabivarin; $V$, vegetative stage.

the $\Delta^{9}$-THC content increased from 25 to $32 \%$ (Lydon et al., 1987), suggesting that $\Delta^{9}$-THC was a UV-B photo-protectant (Pate, 1994). It was further noted that UV-B radiation increases trichome numbers. Altitude may be equally important. Increased solar UV radiation results in higher CBDA, terpene, and cannaflavin content in the hemp variety "Kompolti" (Giupponi et al., 2020). Notably, UV radiation sources used in both studies had relatively broad spectra, compared to electrical UV radiation sources, such UV-discharge lamps and light-emitting diodes (LEDs). It is unknown if there is was an interactive effect between UV-A $(315-380 \mathrm{~nm})$ and UV-B radiation, as a high percentage of UV-A radiation was present in both the UV-B and control light treatments (Mirecki and Teramura, 1984; Lydon et al., 1987; Giupponi et al., 2020). A subsequent study examined the impact of UV-A radiation on cannabinoid accumulation, and reported increased cannabinoid levels other than $\Delta^{9}$-THC (Magagnini et al., 2018). Low percentages of UV-A radiation (2\%) from full-spectrum LED arrays induced an increase of several cannabinoids, including CBD, CBG, $\Delta^{9}$-THC, and tetrahydrocannabivarin (THCV), compared to a high pressure sodium (HPS) lamp that contained $1 \%$ of UVA radiation (Magagnini et al., 2018). Clearly, more studies are required to clarify the impact of UV radiation on cannabis PSM accumulation.

\section{Visible Light and PSM}

The impact of visible light on cannabis PSM accumulation has been investigated with different lighting configurations and different wavelengths (Hawley, 2018; Magagnini et al., 2018; Namdar et al., 2019) (Table 1). A high percentage of blue light cause increased cannabinoid content in cannabis inflorescence (drug-type cannabis, high amount of THC) (Hawley, 2018; Namdar et al., 2019; Danziger and Bernstein, 2021). Hawley (2018) examined the impact of subcanopy lighting with two different light spectra, $440+660 \mathrm{~nm}$ (blue + red, BR) and 440 $+530+660 \mathrm{~nm}$ (blue+ green + red, BGR), on cannabinoid and terpene accumulation. Increased $\Delta^{9}$-THC content and high CBGA levels were observed under both subcanopy BR and BGR lighting. Subcanopy BGR lighting had a higher impact on terpene accumulation than BR lighting, on both upper and lower canopies (Hawley, 2018). Increased CBGA content under LED lighting was similarly reported (Namdar et al., 2019; Danziger and Bernstein, 2021). During the flowering stage, light treatment with rich-blue light from overhead blue-red LED fixtures increased CBGA content and the CBGA: THCA ratio (Namdar et al., 2019).

Conflicting results on the interactive effects between blue light and cannabinoid content, however, were reported recently in fiber-type cannabis (hemp) 
(Wei et al., 2021; Westmoreland et al., 2021). Westmoreland et al. (2021) investigated the impact of light spectra on fiber-type cannabis and reported that neither CBD nor THC accumulation was impacted by spectral quality. The authors reported that this was likely caused by high light level $\left(900 \mu \mathrm{mol} \cdot \mathrm{m}^{-2} \cdot \mathrm{s}^{-1}\right)$ used as the saturation state of photoreceptors was reached, resulting in low sensitivity of cannabinoid accumulation to spectral quality (Westmoreland et al., 2021). Wei et al. (2021) also reported that no significant correlation between blue light fraction and cannabinoid yield was found in fiber-type cannabis; however, note that in this study the light levels used was between 28 and $540 \mu \mathrm{mol} \cdot \mathrm{m}^{-2} \cdot \mathrm{s}^{-1}$. As such, it is unknown that whether such variation on the interactive effect between spectral quality and cannabinoid accumulation is caused by light levels or cannabis chemotypes. Apart from blue light, supplemental green light induced cannabis PSM accumulation, including $\Delta^{9}$-THC and terpenes (limonene, linalool, and myrcene) (Hawley, 2018). No physiological theories explain how supplemental green light induces cannabis PSM accumulation. Clearly, both spectral properties and cannabis chemotype used highly impact cannabinoid accumulation, and further investigation on the links between spectral properties, cannabis chemotype, and photoreceptor is required to clarify the spectral effects.

\section{PHOTOBIOLOGY AND MOLECULAR PATHWAYS IN C. SATIVA L. PSM BIOSYNTHESIS}

Light regimes are elemental to $C$. sativa $\mathrm{L}$. cultivation, as different wavelengths of light activate various light-dependent responses and related gene expression via photoreceptors and enzymes (Eichhorn Bilodeau et al., 2019; Aliferis and BernardPerron, 2020). Although the studies on cannabis growth and photobiology has expanded in the last few years, a comprehensive review by Aliferis and Bernard-Perron (2020) concludes that how light spectra influence cannabis metabolomics is still largely unknown. In particular, how cannabis PSM biosynthesis is impacted by monochromatic light requires further investigation, as most studies to date were conducted under mixed wavelength or full-spectrum light conditions.

Figure 3 summarizes what is known of wavelengths and corresponding C. sativa L. PSM responses. UV radiation, one of the most effective wavelength ranges that induces cannabinoid biosynthesis (THC, THCV, CBD, and CBG), is perceived by several photoreceptors including UVR8, cryptochromes, and phototropins (Sager et al., 1988; Galvão and Fankhauser, 2015). Few studies have attempted to identify the regulatory elements of PSM biosynthetic pathway in cannabis plants (Marks et al., 2009; Bassolino et al., 2020). Some candidate regulatory genes for both cannabinoid and flavonoid biosynthesis(s) have been pinpointed and regulatory proteins identified; CsMYB77 and CsMYB94 for cannabinoid biosynthesis and CsbHLH112 and CsbHLH113 for flavonoid biosynthesis (Bassolino et al., 2020). Both MYB and bHLH superfamilies play key roles in the regulation of secondary metabolism (Hong, 2016). Follow up studies are required to place these cannabis proteins in the cannabinoid and flavonoid

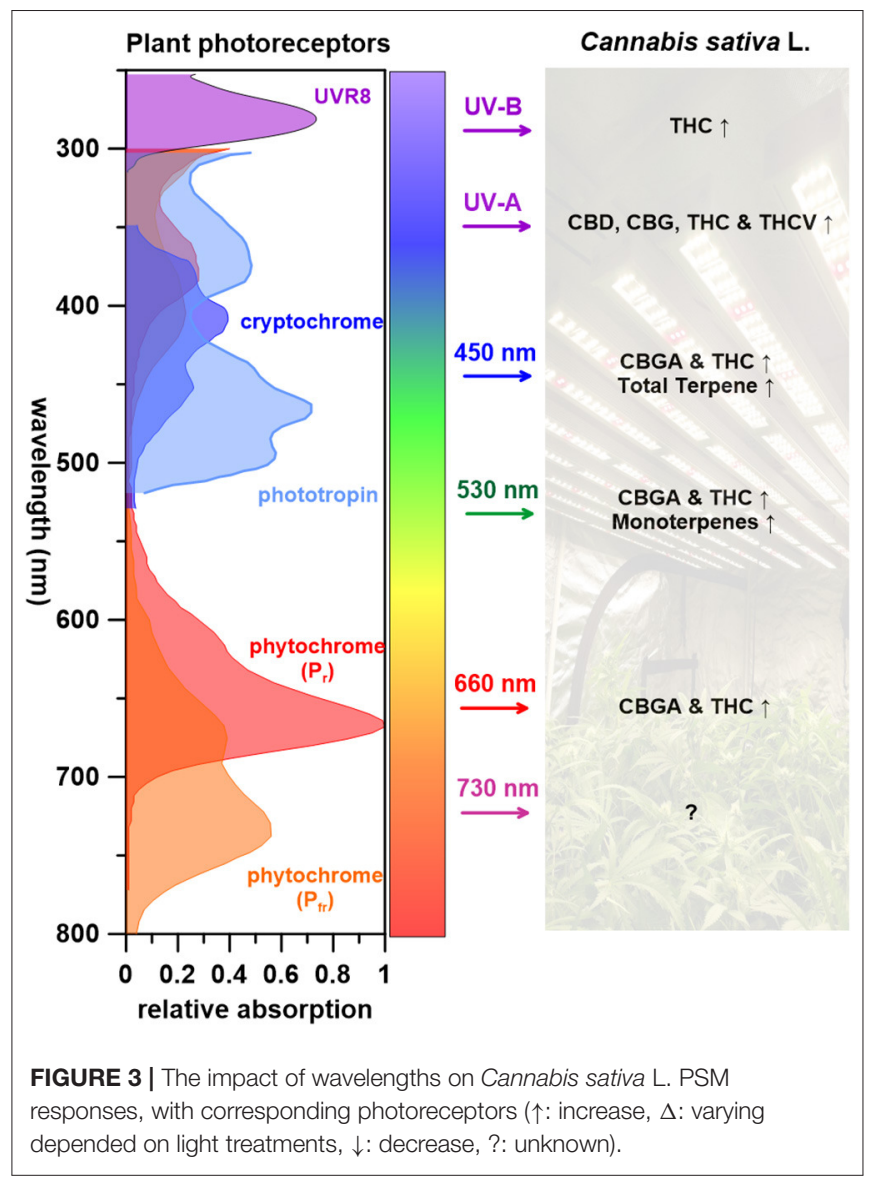

metabolic pathways. As for terpenes, although several studies indicate that UV-B radiation effects higher monoterpene content in plants that contain glandular trichomes (Johnson et al., 1999; Maffei and Scannerini, 2000), this has not yet been reported in $C$. sativa L. to our knowledge.

It has been proposed that light-dependent reactions for photosynthesis occur and supply energy for metabolic activity in tomato (Solanum lycopersicum) type VI glandular trichomes (Balcke et al., 2017). Using this as a precedence, it may be of interest to evaluate the global carbon and energy balance in $C$. sativa $\mathrm{L}$. with different wavelengths of light to further elucidate trichome productivity and phytochemistry. Visible light (450, 530, and $660 \mathrm{~nm}$ ) leads to increased CBGA, THC and terpene contents in C. sativa L. (Figure 3). When shifting wavelengths from UV radiation to the visible spectrum, cannabinoid precursor CBGA levels increases, yet no impact on THC is observed (Hawley, 2018; Namdar et al., 2019). Although Veress et al. (1990) reported that CBGA conversion to cannabinoids are non-enzymatic catalyzed reactions that naturally occurring postharvest during storage or heating (decarboxylation), it appears that light wavelengths can impact specific cannabinoid potency.

How visible light affects terpene biosynthesis remains elusive due to limited studies and terpene diversity (monoterpenes, sesquiterpene, and diterpenes). Drawing from previous studies 
of other crops may provide some insight and future direction for cannabis terpene production (Kessler and Kalske, 2018). When grown under blue LEDs, sage (Pervoskia abrotanoides, from the Lamiaceae family), sees its relative monoterpene content increase 3 -fold upon exposure, with notable increases of $\alpha$-thujene, $\alpha$ pinene, and $\beta$-pinene. It was concluded that blue light could generally promote monoterpene content in $P$. abrotanoides, while augmented production of only one monoterpene, limonene, was observed in P. atriplicifolia. In this species, red light increased $\beta$-myrcene and cis-ocimene content (Ghaffari et al., 2019).

A nascent legal industry with proprietary value slows access to reliable information on indoor cannabis production, postharvest practices and processing of cannabis and cannabisderived products. Apart from controlling environment (light, temperature, nutrients, microbiome etc.) to boost plant phytochemistry, optimal use of light pre- and post-harvest should be considered. For example, UV radiation could be used at the end of the flowering stage or before harvest to increase PSM production. More studies on how light can be manipulated during plant production and post-harvest for consistent PSM production and accumulation are anticipated.

\section{CONCLUDING REMARKS}

Here we review known aspects of photobiology that are relevant to PSM production in C. sativa L., as cannabis research and development efforts are shifting from plant yield performance to manipulating cannabinoid, terpene, and flavonoid content. It is clear that light spectra can be manipulated to target specific cannabis PSM accumulation in different cannabis tissues (leaves and buds), resulting in altered potencies. Practically applied, optimized light regimes should reduce necessary electrical inputs while increasing cannabis PSM yields and quality. UV radiation is a powerful tool for stimulating cannabinoid biosynthesis in cannabis trichomes, while visible light alone impacts specific cannabinoid biosynthesis pathways and PSM profiles. UV radiation impacts terpene biosynthesis in other model plants, and this could be useful for cannabis plants. We expect that UV and blue LEDs will be increasingly used to stimulate desirable cannabis PSMs, as they have been widely applied and tailored to other high-value crops. The majority of cannabis studies

\section{REFERENCES}

Abrams, D. I. (2019). Should oncologists recommend cannabis? Curr. Treat. Options Oncol. 20:59. doi: 10.1007/s11864-019-0659-9

Agati, G., and Tattini, M. (2010). Multiple functional roles of flavonoids in photoprotection. New Phytol. 186, 786-793. doi: 10.1111/j.1469-8137.2010.03269.x

Ahmed, S. A., Ross, S. A., Slade, D., Radwan, M. M., Khan, I. A., and Elsohly, M. A. (2015). Minor oxygenated cannabinoids from high potency Cannabis sativa L. Phytochemistry 117, 194-199. doi: 10.1016/j.phytochem.2015. 04.007

Aizpurua-Olaizola, O., Soydaner, U., ÖztüRk, E., Schibano, D., Simsir, Y., Navarro, P., et al. (2016). Evolution of the cannabinoid and terpene content during the growth of Cannabis sativa plants from different chemotypes. J. Nat. Prod. 79, 324-331. doi: 10.1021/acs.jnatprod.5b00949 are conducted under blue- and red-light mixtures, leaving a large sum of wavelengths in the visible spectrum untouched. Current evidence indicates that visible LED light can enhance $\mathrm{CBG}$, THC, and terpene accumulation, but this is not explicitly seen with $\mathrm{CBD}$. Gene regulatory and molecular pathways affecting cannabis metabolomics under monochromatic light remain elusive. Lighting strategies such as subcanopy lighting and varying light spectra for different plant growing stages and plant architecture can lower energy consumption and optimize cannabis PSM production, eventually improving the precision of cannabis PSM production, as well as therapeutic capacities.

Based on research reviewed, a few experimental directions are proposed to bridge knowledge gaps in cannabis lighting and PSM accumulation research: (1) The impact of narrowspectrum light on cannabis PSM accumulation. Light spectrum greatly impacts cannabis PSM accumulation, yet there is minimal research available on the impact of narrow-spectrum light as most studies were conducted under either dichromatic or full-spectrum lighting. (2) Further investigations into the impact of high light in drug-type cannabis growth and its PSM accumulation, as our current knowledge in cannabis lighting is based on experimentation conducted under 500 $\mu \mathrm{mol} \cdot \mathrm{m}^{-2} \cdot \mathrm{s}^{-1}$. (3) The impact of pre-harvest UV radiation treatment on cannabis PSM accumulation. UV LED sources with different wavelengths are highly available, and the accessibility to both researchers and producers make results more accessible.

\section{AUTHOR CONTRIBUTIONS}

VD and B-SW led the writing of this paper. B-SW and SM were the major editors. SM, VM, and ML contributed over $50 \%$ of the writing for the paper. ML is the correspondence point person. All authors contributed to the article and approved the submitted version.

\section{ACKNOWLEDGMENTS}

The authors would like to thank NSERC (CRDPF 543704-19 and CREATE 543319-2020) and EXKA Inc. for their continuous support and funding of this project. 
Andre, C. M., Hausman, J.-F., and Guerriero, G. (2016). Cannabis sativa: the plant of the thousand and one molecules. Front. Plant Sci. 7:19. doi: $10.3389 /$ fpls.2016.00019

Arena, C., Tsonev, T., Doneva, D., De Micco, V., Michelozzi, M., Brunetti, C., et al. (2016). The effect of light quality on growth, photosynthesis, leaf anatomy and volatile isoprenoids of a monoterpene-emitting herbaceous species (Solanum lycopersicum L.) and an isoprene-emitting tree (Platanus orientalis L.). Environ. Exp. Bot. 130, 122-132. doi: 10.1016/j.envexpbot.2016.05.014

Balcke, G. U., Bennewitz, S., Bergau, N., Athmer, B., Henning, A., Majovsky, P., et al. (2017). Multi-omics of tomato glandular trichomes reveals distinct features of central carbon metabolism supporting high productivity of specialized metabolites. Plant Cell 29, 960-983. doi: 10.1105/tpc.17.00060

Baron, E. P. (2018). Medicinal properties of cannabinoids, terpenes, and flavonoids in cannabis, and benefits in migraine, headache, and pain: an update on current evidence and cannabis science. Headache 58, 1139-1186. doi: 10.1111/head.13345

Barrett, M., Gordon, D., and Evans, F. (1985). Isolation from Cannabis sativa L. of cannflavin - a novel inhibitor of prostaglandin production. Biochem. Pharmacol. 34, 2019-2024. doi: 10.1016/0006-2952(85)90325-9

Barrett, M., Scutt, A., and Evans, F. (1986). Cannflavin A and B, prenylated flavones from Cannabis sativa L. Experientia 42, 452-453. doi: 10.1007/BF02118655

Bassolino, L., Buti, M., Fulvio, F., Pennesi, A., Mandolino, G., Milc, J., et al. (2020). In silico identification of MYB and bHLH families reveals candidate transcription factors for secondary metabolic pathways in Cannabis sativa $L$. Plants 9:1540. doi: 10.3390/plants9111540

Bauer, R., Woelkart, K., and Salo-Ahen, O. M. (2008). CB receptor ligands from plants. Curr. Top. Med. Chem. 8, 173-186. doi: 10.2174/156802608783498023

Benelli, G., Pavela, R., Lupidi, G., Nabissi, M., Petrelli, R., Kamte, S. L. N., et al. (2018). The crop-residue of fiber hemp cv. Futura 75: from a waste product to a source of botanical insecticides. Environ. Sci. Pollut. Res. 25, 10515-10525. doi: 10.1007/s11356-017-0635-5

Blasco-Benito, S., Seijo-Vila, M., Caro-Villalobos, M., Tundidor, I., Andradas, C., García-Taboada, E., et al. (2018). Appraising the "entourage effect": antitumor action of a pure cannabinoid versus a botanical drug preparation in preclinical models of breast cancer. Biochem. Pharmacol. 157, 285-293. doi: 10.1016/j.bcp.2018.06.025

Booth, J. K., and Bohlmann, J. (2019). Terpenes in Cannabis sativa-From plant genome to humans. Plant Sci. 284, 67-72. doi: 10.1016/j.plantsci.2019.03.022

Booth, J. K., Page, J. E., and Bohlmann, J. (2017). Terpene synthases from Cannabis sativa. PLoS ONE 12:e173911. doi: 10.1371/journal.pone.0173911

Bourgaud, F., Gravot, A., Milesi, S., and Gontier, E. (2001). Production of plant secondary metabolites: a historical perspective. Plant Sci. 161, 839-851. doi: 10.1016/S0168-9452(01)00490-3

Brenneisen, R. (2007). "Chemistry and analysis of phytocannabinoids and other Cannabis constituents," in Marijuana and the Cannabinoids, ed M. A. Elsohly. (Totowa, NJ: Human Press), 17-49. doi: 10.1007/978-1-59259-947-9_2

Bruci, Z., Papoutsis, I., Athanaselis, S., Nikolaou, P., Pazari, E., Spiliopoulou, C., et al. (2012). First systematic evaluation of the potency of Cannabis sativa plants grown in Albania. For. Sci. Int. 222, 40-46. doi: 10.1016/j.forsciint.2012.04.032

Chandra, S., Lata, H., and Elsohly, M. A. (2017). Cannabis sativa L.-Botany and Biotechnology. Cham: Springer. doi: 10.1007/978-3-319-54564-6

Christianson, D. W. (2017). Structural and chemical biology of terpenoid cyclases. Chem. Rev. 117, 11570-11648. doi: 10.1021/acs.chemrev.7b00287

Danziger, N., and Bernstein, N. (2021). Light matters: effect of light spectra on cannabinoid profile and plant development of medical cannabis (Cannabis sativa L.). Indus. Crops Prod. 164:113351. doi: 10.1016/j.indcrop.2021.113351

Dao, T., Linthorst, H., and Verpoorte, R. (2011). Chalcone synthase and its functions in plant resistance. Phytochem. Rev. 10:397. doi: 10.1007/s11101-011-9211-7

Dasgupta, N., Beletsky, L., and Ciccarone, D. (2018). Opioid crisis: no easy fix to its social and economic determinants. Am. J. Public Health 108, 182-186. doi: 10.2105/AJPH.2017.304187

Dayanandan, P., and Kaufman, P. B. (1976). Trichomes of Cannabis sativa L. (Cannabaceae). Am. J. Bot. 63, 578-591. doi: 10.1002/j.1537-2197.1976.tb11846.x

Degenhardt, F., Stehle, F., and Kayser, O. (2017). "The biosynthesis of cannabinoids," in Handbook of Cannabis and Related Pathologies, ed V. R. Preedy (Cambridge, MA, Elsevier), 13-23. doi: 10.1016/B978-0-12-800756-3.00002-8
Dolzhenko, Y., Bertea, C. M., Occhipinti, A., Bossi, S., and Maffei, M. E. (2010). UV-B modulates the interplay between terpenoids and flavonoids in peppermint (Mentha $\times$ piperita L.). J. Photochem. Photobiol. B Biol. 100, 67-75. doi: 10.1016/j.jphotobiol.2010.05.003

Downey, M. O., Dokoozlian, N. K., and Krstic, M. P. (2006). Cultural practice and environmental impacts on the flavonoid composition of grapes and wine: a review of recent research. Am. J. Enol. Viticult. 57, 257-268.

Drinić, Z., Vidović, S., Vladić, J., Koren, A., Kiprovski, B., and Sikora, V. (2018). Effect of extraction solvent on total polyphenols content and antioxidant activity of Cannabis sativa L. Lekovite Sirovine 38, 17-21. doi: $10.5937 /$ leksir1838017D

Eichhorn Bilodeau, S., Wu, B.-S., Rufyikiri, A.-S., Macpherson, S., and Lefsrud, M. (2019). An update on plant photobiology and implications for cannabis production. Front. Plant Sci. 10:296. doi: 10.3389/fpls.2019.00296

El-Alfy, A. T., Ivey, K., Robinson, K., Ahmed, S., Radwan, M., Slade, D., et al. (2010). Antidepressant-like effect of $\Delta^{9}$-tetrahydrocannabinol and other cannabinoids isolated from Cannabis sativa L. Pharmacol. Biochem. Behav. 95, 434-442. doi: 10.1016/j.pbb.2010.03.004

Elsohly, M., and Gul, W. (2014). "Constituents of Cannabis sativa”, in Handbook of Cannabis, ed R. G. Pertwee (Oxford: Oxford University Press), 3-22. doi: 10.1093/acprof:oso/9780199662685.003.0001

Elsohly, M. A., Radwan, M. M., Gul, W., Chandra, S., and Galal, A. (2017) "Phytochemistry of Cannabis sativa L.", in Phytocannabinoids, eds A. D. Kinghorn, H. Falk, S. Gibbons, J. I. Kobayashi, and W. Herz (Cham: Springer), 1-36. doi: 10.1007/978-3-319-45541-9_1

Elsohly, M. A., and Slade, D. (2005). Chemical constituents of marijuana: the complex mixture of natural cannabinoids. Life Sci. 78, 539-548. doi: 10.1016/j.lfs.2005.09.011

Fischedick, J. T., Hazekamp, A., Erkelens, T., Choi, Y. H., and Verpoorte, R. (2010). Metabolic fingerprinting of Cannabis sativa L., cannabinoids and terpenoids for chemotaxonomic and drug standardization purposes. Phytochemistry 71, 2058-2073. doi: 10.1016/j.phytochem.2010.10.001

Flores-Sanchez, I. J., and Verpoorte, R. (2008a). PKS activities and biosynthesis of cannabinoids and flavonoids in Cannabis sativa L. plants. Plant Cell Physiol. 49, 1767-1782. doi: 10.1093/pcp/pcn150

Flores-Sanchez, I. J., and Verpoorte, R. (2008b). Secondary metabolism in cannabis. Phytochem. Rev. 7, 615-639. doi: 10.1007/s11101-008-9094-4

Frassinetti, S., Moccia, E., Caltavuturo, L., Gabriele, M., Longo, V., Bellani, L., et al. (2018). Nutraceutical potential of hemp (Cannabis sativa L.) seeds and sprouts. Food Chem. 262, 56-66. doi: 10.1016/j.foodchem.2018.04.078

Friedman, D., and Devinsky, O. (2015). Cannabinoids in the treatment of epilepsy. N. Engl. J. Med. 373, 1048-1058. doi: 10.1056/NEJMra1407304

Gagne, S. J., Stout, J. M., Liu, E., Boubakir, Z., Clark, S. M., and Page, J. E. (2012). Identification of olivetolic acid cyclase from Cannabis sativa reveals a unique catalytic route to plant polyketides. Proc. Natl. Acad. Sci. U.S.A. 109, 12811-12816. doi: 10.1073/pnas.1200330109

Gallily, R., Yekhtin, Z., and Hanuš, L. O. (2015). Overcoming the bell-shaped doseresponse of cannabidiol by using cannabis extract enriched in cannabidiol. Pharmacol. Pharmacy 6:75. doi: 10.4236/pp.2015.62010

Galvão, V. C., and Fankhauser, C. (2015). Sensing the light environment in plants: photoreceptors and early signaling steps. Curr. Opin. Neurobiol. 34, 46-53. doi: 10.1016/j.conb.2015.01.013

Gaoni, Y., and Mechoulam, R. (1966). Cannabichromene, a new active principle in hashish. Chem. Commun. 1966, 20-21. doi: 10.1039/c19660000020

Garb, S. (1981). Cannabinoids in the management of severe nausea and vomiting from cancer chemotherapy. Some additional considerations. J. Clin. Pharmacol. 21, 57S-59S. doi: 10.1002/j.1552-4604.1981.tb02574.x

Gertsch, J., Leonti, M., Raduner, S., Racz, I., Chen, J.-Z., Xie, X.-Q., et al. (2008). Beta-caryophyllene is a dietary cannabinoid. Proc. Natl. Acad. Sci. U.S.A. 105, 9099-9104. doi: 10.1073/pnas.0803601105

Ghaffari, Z., Rahimmalek, M., and Sabzalian, M. R. (2019). Variation in the primary and secondary metabolites derived from the isoprenoid pathway in the Perovskia species in response to different wavelengths generated by light emitting diodes (LEDs). Indus. Crops Prod. 140:111592. doi: 10.1016/j.indcrop.2019.111592

Giupponi, L., Leoni, V., Pavlovic, R., and Giorgi, A. (2020). Influence of altitude on phytochemical composition of hemp inflorescence: a metabolomic approach. Molecules 25:1381. doi: 10.3390/molecules25061381 
Goldstein, B. (2016). Cannabis in the Treatment of Pediatric Epilepsy. Chicago, IL: O'Shaughnessy's, 7-9.

Gonçalves, J., Rosado, T., Soares, S., Simão, A. Y., Caramelo, D., Luís, Â., et al. (2019). Cannabis and its secondary metabolites: their use as therapeutic drugs, toxicological aspects, and analytical determination. Medicines 6:31. doi: $10.3390 /$ medicines6010031

Grof, C. P. (2018). Cannabis, from plant to pill. Br. J. Clin. Pharmacol. 84, 2463-2467. doi: 10.1111/bcp.13618

Günnewich, N., Page, J. E., Köllner, T. G., Degenhardt, J., and Kutchan, T. M. (2007). Functional expression and characterization of trichome-specific $(-)$-limonene synthase and $(+)-\alpha-$ pinene synthase from Cannabis sativa. Nat. Prod. Commun. 2:1934578X0700200301. doi: 10.1177/1934578X07002 00301

Gupta, S. K., Sharma, M., Deeba, F., and Pandey, V. (2017). "Plant response: UV-B avoidance mechanisms," in UV-B Radiation: From Environmental Stressor to Regulator of Plant Growth, eds V. P. Singh, S. M. Prasad, and P. Parihar (West Sussex: Wiley-Blackwell), 217-258. doi: 10.1002/9781119143611. $\operatorname{ch} 12$

Hammond, C. T., and Mahlberg, P. G. (1977). Morphogenesis of capitate glandular hairs of Cannabis sativa (Cannabaceae). Am. J. Bot. 64, 1023-1031. doi: 10.1002/j.1537-2197.1977.tb11948.x

Hawley, D. (2018). The influence of spectral quality of light on plant secondary metabolism and photosynthetic acclimation to light quality (Ph.D. dissertation). University of Guelph, Guelph, ON, Canada.

Hazekamp, A. (2007). Cannabis; extracting the medicine. Amsterdam: Print Partners Ipskamp.

Hazekamp, A., and Fischedick, J. (2012). Cannabis-from cultivar to chemovar. Drug Test. Anal. 4, 660-667. doi: 10.1002/dta.407

Hesami, M., Pepe, M., Alizadeh, M., Rakei, A., Baiton, A., and Jones, A. M. P. (2020). Recent advances in cannabis biotechnology. Indus. Crops Prod. 158:113026. doi: 10.1016/j.indcrop.2020.113026

Hilderbrand, R. (2018). Hemp and cannabidiol: what is a medicine? Mol. Med. 115:306.

Hong, J. C. (2016). "General aspects of plant transcription factor families," in Plant Transcription Factors, ed D. H. Gonzalez (Amsterdam: Elsevier), 35-56. doi: 10.1016/B978-0-12-800854-6.00003-8

Huchelmann, A., Boutry, M., and Hachez, C. (2017). Plant glandular trichomes: natural cell factories of high biotechnological interest. Plant Physiol. 175, 6-22. doi: 10.1104/pp.17.00727

Hudson, J. (1963). "Humulones, lupulones and other constituents of hops," in Modern Methods of Plant Analysis/Moderne Methoden der Pflanzenanalyse, eds K. Paech and M. V. Tracey. (Berlin; Heidelberg: Springer), 135-154. doi: 10.1007/978-3-642-94878-7_8

Hunter, W. N. (2007). The non-mevalonate pathway of isoprenoid precursor biosynthesis. J. Biol. Chem. 282, 21573-21577. doi: 10.1074/jbc.R700005200

Hutchison, K. E., Bidwell, L. C., Ellingson, J. M., and Bryan, A. D. (2019). Cannabis and health research: rapid progress requires innovative research designs. Value Health 22, 1289-1294. doi: 10.1016/j.jval.2019.05.005

Izzo, L., Castaldo, L., Narváez, A., Graziani, G., Gaspari, A., Rodríguez-Carrasco, Y., et al. (2020). Analysis of phenolic compounds in commercial Cannabis sativa L. inflorescences using UHPLC-Q-orbitrap HRMS. Molecules 25:631. doi: 10.3390/molecules25030631

Jenkins, G. I. (2017). Photomorphogenic responses to ultraviolet-B light. Plant Cell Environ. 40, 2544-2557. doi: 10.1111/pce.12934

Jin, D., Dai, K., Xie, Z., and Chen, J. (2020). Secondary metabolites profiled in cannabis inflorescences, leaves, stem barks, and roots for medicinal purposes. Sci. Rep. 10, 1-14. doi: 10.1038/s41598-020-60172-6

Jin, D., Jin, S., and Chen, J. (2019). Cannabis indoor growing conditions, management practices, and post-harvest treatment: a review. Am. J. Plant Sci. 10, 925-946. doi: 10.4236/ajps.2019.106067

Johnson, C. B., Kirby, J., Naxakis, G., and Pearson, S. (1999). Substantial UVB-mediated induction of essential oils in sweet basil (Ocimum basilicum L.). Phytochemistry 51, 507-510. doi: 10.1016/S0031-9422(98)00767-5

Johnson, J. R., Burnell-Nugent, M., Lossignol, D., Ganae-Motan, E. D., Potts, R., and Fallon, M. T. (2010). Multicenter, double-blind, randomized, placebocontrolled, parallel-group study of the efficacy, safety, and tolerability of THC: CBD extract and THC extract in patients with intractable cancer-related pain. J. Pain Sympt. Manage. 39, 167-179. doi: 10.1016/j.jpainsymman.2009.06.008
Kessler, A., and Halitschke, R. (2007). Specificity and complexity: the impact of herbivore-induced plant responses on arthropod community structure. Curr. Opin. Plant Biol. 10, 409-414. doi: 10.1016/j.pbi.2007.06.001

Kessler, A., and Kalske, A. (2018). Plant secondary metabolite diversity and species interactions. Annu. Rev. Ecol. Evol. Syst. 49, 115-138. doi: 10.1146/annurev-ecolsys-110617-062406

Knudsen, J. T., Eriksson, R., Gershenzon, J., and Ståhl, B. (2006). Diversity and distribution of floral scent. Bot. Rev. 72, 1-120. doi: 10.1663/0006-8101(2006)72(1:DADOFS)2.0.CO;2

Krishnamurti, C., and Rao, S. C. (2016). The isolation of morphine by Serturner. Indian J. Anaesth. 60:861. doi: 10.4103/0019-5049.193696

Kulkarni, R., Pandit, S., Chidley, H., Nagel, R., Schmidt, A., Gershenzon, J., et al. (2013). Characterization of three novel isoprenyl diphosphate synthases from the terpenoid rich mango fruit. Plant Physiol. Biochem. 71, 121-131. doi: 10.1016/j.plaphy.2013.07.006

Kushima, H., Shoyama, Y., and Nishioka, I. (1980). Cannabis. Xii. Variations of cannabinoid contents in several strains of Cannabis sativa L. with leaf-age, season and sex. Chem. Pharmaceut. Bull. 28, 594-598. doi: 10.1248/cpb.28.594

Labandeira, C. (2005). Invasion of the continents: cyanobacterial crusts to tree-inhabiting arthropods. Trends Ecol. Evol. 20, 253-262. doi: 10.1016/j.tree.2005.03.002

Lapinjoki, S. P., Elo, H. A., and Taipale, H. T. (1991). Development and structure of resin glands on tissues of Betula pendula Roth, during growth. New Phytol. 117, 219-223. doi: 10.1111/j.1469-8137.1991.tb04902.x

Levin, D. A. (1973). The role of trichomes in plant defense. Q. Rev. Biol. 48, 3-15. doi: $10.1086 / 407484$

Lichtenthaler, H. K. (1999). The 1-deoxy-D-xylulose-5-phosphate pathway of isoprenoid biosynthesis in plants. Annu. Rev. Plant Biol. 50, 47-65. doi: 10.1146/annurev.arplant.50.1.47

Lipphardt, S., Brettschneider, R., Kreuzaler, F., Schell, J., and Dangl, J. L. (1988). UV-inducible transient expression in parsley protoplasts identifies regulatory cis-elements of a chimeric Antirrhinum majus chalcone synthase gene. EMBO J. 7, 4027-4033. doi: 10.1002/j.1460-2075.1988.tb03296.x

Livingston, S. J., Quilichini, T. D., Booth, J. K., Wong, D. C., Rensing, K. H., Laflamme-Yonkman, J., et al. (2020). Cannabis glandular trichomes alter morphology and metabolite content during flower maturation. Plant J. 101, 37-56. doi: 10.1111/tpj.14516

Luo, X., Reiter, M. A., D’espaux, L., Wong, J., Denby, C. M., Lechner, A., et al. (2019). Complete biosynthesis of cannabinoids and their unnatural analogues in yeast. Nature 567, 123-126. doi: 10.1038/s41586-019-0978-9

Lydon, J., Teramura, A. H., and Coffman, C. B. (1987). UV-B radiation effects on photosynthesis, growth and cannabinoid production of two Cannabis sativa chemotypes. Photochem. Photobiol. 46, 201-206. doi: 10.1111/j.1751-1097.1987.tb04757.x

Maffei, M., and Scannerini, S. (2000). UV-B effect on photomorphogenesis and essential oil composition in peppermint (Mentha piperita L.). J. Essent. Oil Res. 12, 523-529. doi: 10.1080/10412905.2000.9712150

Magagnini, G., Grassi, G., and Kotiranta, S. (2018). The effect of light spectrum on the morphology and cannabinoid content of Cannabis sativa L. Med. Cannabis Cannabinoids 1, 19-27. doi: 10.1159/000489030

Mao, J., Price, D., Lu, J., Keniston, L., and Mayer, D. (2000). Two distinctive antinociceptive systems in rats with pathological pain. Neurosci. Lett. 280, 13-16. doi: 10.1016/S0304-3940(99)00998-2

Marks, M. D., Tian, L., Wenger, J. P., Omburo, S. N., Soto-Fuentes, W., $\mathrm{He}$, J., et al. (2009). Identification of candidate genes affecting $\Delta^{9}$ tetrahydrocannabinol biosynthesis in Cannabis sativa. J. Exp. Bot. 60, 3715-3726. doi: 10.1093/jxb/erp210

Mcgarvey, D. J., and Croteau, R. (1995). Terpenoid metabolism. Plant Cell 7:1015. doi: $10.2307 / 3870054$

Mcpartland, J. M. (1997). Cannabis as repellent and pesticide. J. Int. Hemp Assoc. 4, 89-94.

Mechoulam, R., and Gaoni, Y. (1965). Hashish-IV: The isolation and structure of cannabinolic, cannabidiolic, and cannabigerolic acids. Tetrahedron 21, 1223-1229. doi: 10.1016/0040-4020(65)80064-3

Mirecki, R. M., and Teramura, A. H. (1984). Effects of ultraviolet-B irradiance on soybean: V. The dependence of plant sensitivity on the photosynthetic photon flux density during and after leaf expansion. Plant Physiol. 74, 475-480. doi: $10.1104 /$ pp.74.3.475 
Moccia, S., Russo, M., Spagnuolo, C., Tedesco, I., Picariello, G., Siano, F., et al. (2019). Activation of cytostatic autophagy by polar extract of hempseed oil (Cannabis sativa L.) in a colorectal adenocarcinoma cell line. Nutr. Metab. Cardiovasc. Dis. 29:871. doi: 10.1016/j.numecd.2019.05.003

Mudge, E. M., Brown, P. N., and Murch, S. J. (2019). The terroir of Cannabis: terpene metabolomics as a tool to understand Cannabis sativa selections. Planta Medica 85, 781-796. doi: 10.1055/a-0915-2550

Namdar, D., Charuvi, D., Ajjampura, V., Mazuz, M., Ion, A., Kamara, I., et al. (2019). LED lighting affects the composition and biological activity of Cannabis sativa secondary metabolites. Indus. Crops Prod. 132, 177-185. doi: 10.1016/j.indcrop.2019.02.016

Nazari, M., and Zarinkamar, F. (2020). Ultraviolet-B induced changes in Mentha aquatica (a medicinal plant) at early and late vegetative growth stages: investigations at molecular and genetic levels. Indus. Crops Prod. 154:112618. doi: 10.1016/j.indcrop.2020.112618

Nützmann, H. W., Huang, A., and Osbourn, A. (2016). Plant metabolic clustersfrom genetics to genomics. New Phytol. 211, 771-789. doi: 10.1111/nph.13981

Okada, T., Mochamad Afendi, F., Altaf-Ul-Amin, M., Takahashi, H., Nakamura, K., and Kanaya, S. (2010). Metabolomics of medicinal plants: the importance of multivariate analysis of analytical chemistry data. Curr. Comput. Aided Drug Design 6, 179-196. doi: 10.2174/157340910791760055

Pate, D. W. (1994). Chemical ecology of Cannabis. J. Int. Hemp Assoc. 2, 32-37.

Pavlovic, R., Panseri, S., Giupponi, L., Leoni, V., Citti, C., Cattaneo, C., et al. (2019). Phytochemical and ecological analysis of two varieties of hemp (Cannabis sativa L.) grown in a mountain environment of Italian Alps. Front. Plant Sci. 10:1265. doi: $10.3389 /$ fpls.2019.01265

Pellati, F., Brighenti, V., Sperlea, J., Marchetti, L., Bertelli, D., and Benvenuti, S. (2018). New methods for the comprehensive analysis of bioactive compounds in Cannabis sativa L. (hemp). Molecules 23:2639. doi: 10.3390/molecules23102639

Pillemer, E. A., and Tingey, W. M. (1976). Hooked trichomes: a physical plant barrier to a major agricultural pest. Science 193, 482-484. doi: 10.1126/science.193.4252.482

Piluzza, G., Delogu, G., Cabras, A., Marceddu, S., and Bullitta, S. (2013). Differentiation between fiber and drug types of hemp (Cannabis sativa L.) from a collection of wild and domesticated accessions. Genet. Resour. Crop Evol. 60, 2331-2342. doi: 10.1007/s10722-013-0001-5

Pollastro, F., Minassi, A., and Fresu, L. G. (2018). Cannabis phenolics and their bioactivities. Curr. Med. Chem. 25, 1160-1185. doi: 10.2174/0929867324666170810164636

Radwan, M. M., Elsohly, M. A., Slade, D., Ahmed, S. A., Wilson, L., El-Alfy, A. T., et al. (2008). Non-cannabinoid constituents from a high potency Cannabis sativa variety. Phytochemistry 69, 2627-2633. doi: 10.1016/j.phytochem.2008.07.010

Raman, V., Lata, H., Chandra, S., Khan, I. A., and Elsohly, M. A. (2017). "Morphoanatomy of marijuana (Cannabis sativa L.)," in Cannabis sativa L.-Botany and Biotechnology, eds S. Chandra, H. Lata, and M.A. Elsohly (Cham: Springer), 123-136. doi: 10.1007/978-3-319-54564-6_5

Rea, K. A., Casaretto, J. A., Al-Abdul-Wahid, M. S., Sukumaran, A., Geddes-Mcalister, J., Rothstein, S. J., et al. (2019). Biosynthesis of cannflavins A and B from Cannabis sativa L. Phytochemistry 164, 162-171. doi: 10.1016/j.phytochem.2019.05.009

Rozema, J., Björn, L. O., Bornman, J., Gaberščik, A., Häder, D.-P., Trošt, T., et al. (2002). The role of UV-B radiation in aquatic and terrestrial ecosystems-an experimental and functional analysis of the evolution of UV-absorbing compounds. J. Photochem. Photobiol. B Biol. 66, 2-12. doi: 10.1016/S1011-1344(01)00269-X

Russo, E. B. (2019). The case for the entourage effect and conventional breeding of clinical cannabis: no "strain," no gain. Front. Plant Sci. 9:1969. doi: 10.3389/fpls.2018.01969

Ruzicka, L. (1953). The isoprene rule and the biogenesis of terpenic compounds. Experientia 9, 357-367. doi: 10.1007/BF02167631

Sager, J., Smith, W., Edwards, J., and Cyr, K. (1988). Photosynthetic efficiency and phytochrome photoequilibria determination using spectral data. Trans. ASAE 31, 1882-1889. doi: 10.13031/2013.30952

Seca, A. M., and Pinto, D. C. (2019). Biological potential and medical use of secondary metabolites. Medicines 6:66. doi: 10.3390/medicines6020066
Shoyama, Y., Oku, R., Yamauchi, T., and Nishioka, I. (1972). Cannabis. VI. Cannabicyclolic acid. Chem. Pharmaceut. Bull. 20, 1927-1930. doi: $10.1248 / \mathrm{cpb} .20 .1927$

Siano, F., Moccia, S., Picariello, G., Russo, G. L., Sorrentino, G., Di Stasio, M., et al. (2019). Comparative study of chemical, biochemical characteristic and ATR-FTIR analysis of seeds, oil and flour of the edible fedora cultivar hemp (Cannabis sativa L.). Molecules 24:83. doi: 10.3390/molecules24010083

Sirikantaramas, S., Morimoto, S., Shoyama, Y., Ishikawa, Y., Wada, Y., Shoyama, Y., et al. (2004). The gene controlling marijuana psychoactivity molecular cloning and heterologous expression of $\Delta^{1}$-tetrahydrocannabinolic acid synthase from Cannabis sativa L. J. Biol. Chem. 279, 39767-39774. doi: $10.1074 /$ jbc.M403693200

Sirikantaramas, S., and Taura, F. (2017). "Cannabinoids: biosynthesis and biotechnological applications," in Cannabis sativa L.-Botany and Biotechnology, eds S. Chandra, H. Lata, and M. A. Elsohly (Cham: Springer), 183-206. doi: 10.1007/978-3-319-54564-6_8

Small, E., and Naraine, S. G. (2016). Size matters: evolution of large drug-secreting resin glands in elite pharmaceutical strains of Cannabis sativa (marijuana). Genet. Resour. Crop Evol. 63, 349-359. doi: 10.1007/s10722-015-0254-2

Solymosi, K., and Köfalvi, A. (2017). Cannabis: a treasure trove or pandora's box? Mini Rev. Med. Chem. 17, 1223-1291. doi: 10.2174/1389557516666161004162133

Stojanoski, N. (1999). Development of health culture in Veles and its region from the past to the end of the 20th century. Veles Soc. Sci. 13, 13-34.

Taghinasab, M., and Jabaji, S. (2020). Cannabis microbiome and the role of endophytes in modulating the production of secondary metabolites: an overview. Microorganisms 8:355. doi: 10.3390/microorganisms8030355

Taura, F., Sirikantaramas, S., Shoyama, Y., Yoshikai, K., Shoyama, Y., and Morimoto, S. (2007). Cannabidiolic-acid synthase, the chemotype-determining enzyme in the fiber-type Cannabis sativa. FEBS Lett. 581, 2929-2934. doi: 10.1016/j.febslet.2007.05.043

Teramura, A. H. (1983). Effects of ultraviolet-B radiation on the growth and yield of crop plants. Physiol. Plant. 58, 415-427. doi: 10.1111/j.1399-3054.1983.tb04203.x

Theis, N., and Lerdau, M. (2003). The evolution of function in plant secondary metabolites. Int. J. Plant Sci. 164, S93-S102. doi: 10.1086/374190

Thirumurugan, D., Cholarajan, A., Raja, S. S., and Vijayakumar, R. (2018). "An introductory chapter: secondary metabolites," in Secondary Metabolites - Sources and Applications, ed R. Vijayakumar (London: IntechOpen), 3-21. doi: 10.5772/intechopen.79766

Tissier, A. (2012). Glandular trichomes: what comes after expressed sequence tags? Plant J. 70, 51-68. doi: 10.1111/j.1365-313X.2012.04913.x

Tomko, A. M., Whynot, E. G., Ellis, L. D., and Dupré, D. J. (2020). Anti-cancer potential of cannabinoids, terpenes, and flavonoids present in cannabis. Cancers 12:1985. doi: $10.3390 /$ cancers 12071985

Tossi, V. E., Regalado, J. J., Iannicelli, J., Laino, L. E., Burrieza, H. P., Escandón, A. S., et al. (2019). Beyond Arabidopsis: differential UV-B response mediated by UVR8 in diverse species. Front. Plant Sci. 10:780. doi: 10.3389/fpls.2019. 00780

Turner, C. E., Elsohly, M. A., and Boeren, E. G. (1980). Constituents of Cannabis sativa L. XVII. A review of the natural constituents. J. Nat. Prod. 43, 169-234. doi: 10.1021/np50008a001

Urban, L., Charles, F., De Miranda, M. R. A., and Aarrouf, J. (2016). Understanding the physiological effects of UV-C light and exploiting its agronomic potential before and after harvest. Plant Physiol. Biochem. 105, 1-11. doi: 10.1016/j.plaphy.2016.04.004

Van Klingeren, B., and Ten Ham, M. (1976). Antibacterial activity of $\Delta^{9}$ tetrahydrocannabinol and cannabidiol. Antonie van Leeuwenhoek 42, 9-12. doi: 10.1007/BF00399444

Vanhove, W., Van Damme, P., and Meert, N. (2011). Factors determining yield and quality of illicit indoor cannabis (Cannabis spp.) production. Forensic Sci. Int. 212, 158-163. doi: 10.1016/j.forsciint.2011.06.006

Veress, T., Szanto, J., and Leisztner, L. (1990). Determination of cannabinoid acids by high-performance liquid chromatography of their neutral derivatives formed by thermal decarboxylation: I. Study of the decarboxylation process in open reactors. J. Chromatogr. A 520, 339-347. doi: 10.1016/0021-9673(90)85118-F 
Warner, R., Wu, B.-S., Macpherson, S., and Lefsrud, M. (2021). A review of strawberry photobiology and fruit flavonoids in controlled environments. Front. Plant Sci. 12:611893. doi: 10.3389/fpls.2021.611893

Wei, X., Zhao, X., Long, S., Xiao, Q., Guo, Y., Qiu, C., et al. (2021). Wavelengths of LED light affect the growth and cannabidiol content in Cannabis sativa L. Indus.l Crops Prod. 165:113433. doi: 10.1016/j.indcrop.2021. 113433

Werker, E. (2000). Trichome diversity and development. Adv. Bot. Res. 31, 1-35. doi: 10.1016/S0065-2296(00)31005-9

Westmoreland, F. M., Kusuma, P., and Bugbee, B. (2021). Cannabis lighting: decreasing blue photon fraction increases yield but efficacy is more important for cost effective production of cannabinoids. PLoS ONE 16:e248988. doi: 10.1371/journal.pone.0248988

White, A., Munson, J., Munson, A., and Carchman, R. (1976). Effects of $\Delta 9$ tetrahydrocannabinol in Lewis lung adenocarcinoma cells in tissue culture. J. Natl. Cancer Inst. 56, 655-658. doi: 10.1093/jnci/56.3.655
Zhou, F., and Pichersky, E. (2020). More is better: the diversity of terpene metabolism in plants. Curr. Opin. Plant Biol. 55, 1-10. doi: $10.1016 /$ j.pbi.2020.01.005

Conflict of Interest: The authors declare that this study received funding from EXKA Inc. The funder was not involved in the study design, collection, analysis, interpretation of data, the writing of this article or the decision to submit for publication.

Copyright (c) 2021 Desaulniers Brousseau, Wu, MacPherson, Morello and Lefsrud. This is an open-access article distributed under the terms of the Creative Commons Attribution License (CC BY). The use, distribution or reproduction in other forums is permitted, provided the original author(s) and the copyright owner(s) are credited and that the original publication in this journal is cited, in accordance with accepted academic practice. No use, distribution or reproduction is permitted which does not comply with these terms. 